\title{
The Emphasis on the Relevant Needs of the Parents of Extremely Premature Infants with Special Regard to the Impact of COVID-19
}

\author{
J. Masan (Jan Masan)1, K. Kolejak (Kamil Kolejak)²,
}

M. Hamarova (Mariana Hamarova) $)^{3}$

${ }^{1}$ University of Thessaly, Greece.

${ }^{1}$ University of Ss. Cyril \& Methodius in Trnava, Slovakia.

${ }^{2}$ Constantine the Philosopher University in Nitra, Slovakia.

${ }^{3}$ St. Elizabeth University of Health and Social Sciences, Bratislava, Slovakia.

\section{E-mail address:}

masanjan@gmail.com

\section{Reprint address:}

Jan Masan

Nálepkova 1

92101 Piestany

Slovakia

Source: Clinical Social Work and Health Intervention

Pages: $9-14$

Volume: 12

Issue: 1

\section{Reviewers:}

Andrea Shahum

University of North Carolina at Chapel Hill School of Medicine, USA

Pawel S. Czarnecki,

Rector of the Warsaw Management University, Poland

\section{Keywords:}

Extremely premature infant. Stress. Depression. Post-traumatic stress disorder. Parental needs. Social support. Stress management. Impact of COVID-19.

\section{Publisher:}

International Society of Applied Preventive Medicine i-gap

CSWHI 2021; 12(1): 9 - 14; DOI: 10.22359/cswhi_12_1_01 (C) Clinical Social Work and Health Intervention

\section{Abstract:}

This article draws from the results of a survey that was aimed at giving an overview and exploring in detail what needs the parents of extremely premature infants have and what options of social support they are provided with, especially during the period of the spread and subsequent impact of the COVID-19 pandemic. The research took place from the beginning of February 2020 until the beginning of September 2020. In the 
survey, 30 families participated from various countries, including Italy, Spain, the United States, Great Britain, Poland, Romania, and Ukraine. The results of this survey can be applied to produce analyses that will serve as the basis for future relevant and innovative research on the impact of COVID-19 on the global population.

\section{Introduction}

Physicians and medical staff currently succeed in saving extremely premature infants with an increasingly lower gestational age and birth weight, often under the established rate of survival. It is the group of newborns that is considered to be at the highest risk with respect to survival, possible complications, and the uncertainty of any prognoses. However, more and more parents owe their child's life and health to progress in neonatology. The expectations of parents, gynecologists, neonatologists and other specialists in this field may exceed the limits of what can be achieved in rescuing these children (5). Even in the medical specialties that progress rapidly they aren't always able to sustain health and life of all children (5). Therefore, the extremely premature infants require long-term special care and enormous patience not only on the part of health workers but, especially, parents. The parents, particularly the mother, are confronted with an unexpected situation for which they have had neither opportunity nor time to prepare. The effort aimed at saving the infant while separating the newborn from the mother immediately following delivery also represents the starting point of a long-term stressful process that involves both parents. During this process, they are forced to adapt to an abnormal and unforeseen situation, while facing the fear for the life of the infant, his or her health, future, and many other related negative sentiments. The article draws from the results of a survey that sought to provide an overview and explore in detail what needs the parents of extremely premature infants have and what options of social support they are provided with especially during the period of the spread and subsequent impact of the COVID-19 pandemic.

\section{Methods and findings}

The research took place from the beginning of February 2020 until the beginning of September 2020 . In the survey, 30 families participated from various countries, including Italy, Spain, the United States, Great Britain, Poland, Romania, and Ukraine. The families were approached through different non-governmental organizations and international interest groups involved in helping the parents of children with disabilities. Many of these infants were born extremely premature. Contacting the parents through such organizations provided necessary credibility as the parents had an opportunity to make sure that the authors of the article had many years of experience in this field. The survey was conducted by way of qualitative research methods, the main tool being an in-depth online interview with each family separately. The respondents were the parents of extremely premature infants aged 20-44. Before the survey started, they had agreed to the implementation of focus groups. The focus groups highlighted several crucial areas that ought to be prioritized when providing the parents with support, especially during the period of the spread and subsequent impact of the COVID19 pandemic. To a certain degree, the limiting factors of the research include its relatively short duration and the fact that the follow-up part of the survey is still under way; therefore, the results cannot be applied to the global population (yet).

The focus groups have shown that the fact that their baby was born as extremely premature lead the parents to ask themselves a series of questions that are very difficult to answer: Why our baby? What is the reason? What will the future development of our baby be? How is it going to affect our family? It is particularly the ,Why?“ question that is not actually a question but rather an expression of pain, fear, acrimony, anger, despair or hopelessness. In this situation, both parents need such a form of social support that would not only help them cope with the demanding new circumstances but also foster their selfesteem and self-appraisal and improve their skills to face the problem and find possible solutions to the new situation. Furthermore, the parents need significant support in their attempt to estab- 
lish a relationship with their baby. When coming to terms with a premature birth and its potential negative effects for the infant, the decisive role is played by the closest surroundings of the parents, their closest relatives and friends, and the medical staff with whom the parents remain in everyday contact on a long-term basis. However, the parents frequently have negative experience that even people in their surroundings and health workers do not know how to communicate with them, nor how to alleviate the situation for them. In addition, they were not provided efficient assistance or support in overcoming the anxiety and fear of the spread and subsequent impact of the Coronavirus pandemic. In this regard, they often expressed concern about the COVID-19 pandemic and its impact on the health of their child as well as on the future economic and social life of their family.

With respect to the focus group results, research was concentrated on following areas:

- in case of an extremely premature infant the parents need - from the perspective of the content of social support - emotional support during the entire hospitalization of the infant and the subsequent home care. This emotional support should seek to provide the parents with positive emotions by, for example, trying to be understanding; supplying hope, appeasement, affection, emotional proximity, empathy, kindness, and consolation; expressing interest in the parents' situation; building trust; and, fostering empathic listening thanks to which the parents may acquire a sense of security and acceptance and start gradually gaining confidence. The emotional support also includes the presence of the relatives and psychological or psychotherapeutic assistance for the parents, especially the mothers, during the hospitalization period and the subsequent home care. In addition to the emotional support the parents also need evaluation support that finds its expression in esteem, respect, appreciation, and the way people behave toward them. Such an attitude helps the parents be assured of their value and foster their self-esteem and effort to solve the situation independently. Thus, it becomes a positive source of their self-appraisal. Further, the parents of extremely premature infants need social support that provides guidance, social support that provides feedback, and individual social support. In connection with the altered types of social support and the provision of assistance to parents of extremely premature infants, there is also an ,urgent need to find a correct perspective on life as a whole again" (4). It is therefore necessary that the provision of social support begins with active listening. However, it is not only about what the parents say but also about understanding and comprehending what they seek to communicate (2);

- with respect to child care, the parents need instrumental social support, including household assistance, daily childcare assistance, and the provision of material things. Another necessity for the parents is informational social support that aims at helping them to get acquainted with further prognoses, the information concerning the condition and possible future development of their child, contact details for additional experts, and the particularities of childcare;

- the parents need to be continuously assured by people in their surroundings and medical staff that they can handle the emerged situation. Further, they need to share their concerns and experiences with other parents of extremely premature infants, often establishing and maintaining contacts and even friendships with them also at the international level through, for example, various international organizations. It is helpful when they see other extremely premature infants grow and flourish and when they feel they can ask about relevant problems that are of interest to them;

- the parents of extremely premature infants often face the downplaying, or else dramatizing, of their situation on the part of their family, surroundings or even health workers. On the contrary, for parents of extremely premature infants it is necessary to experience a strengthening approach: the so-called volitional positive attitude that encompasses acceptance and willingness to maintain contacts, and an intellectual positive attitude based on recognition and respect for them as parents (6). However, based on the experience of parents, they rather encounter unwillingness to perceive their situation more tactfully and with a more human approach, and a negative evaluation of, for example, their characteristics as parents (6). Accord- 
ing to the parents, they were shocked by the insensitive attitude of physicians and medical staff during communication or in the situations when they felt the need to see their child. Similarly, they are often subject to unpleasant questions from the medical staff or family;

- during the period when the fear of the COVID19 pandemic peaked the parents were not provided by the physicians and medical staff with efficient support that would have helped them manage their anxiety. Even today, the parents remain very concerned that they never received answers to some questions that were relevant for them. According to the parents, it was precisely the answers to these queries that would have helped them acquire a sense of perspective. In this respect, the survey focused on practicing mindful behavior with the parents of extremely premature infants as one of the most efficient psychological tools of managing the current impact of COVID-19. Developing a mindful approach involves therapeutic methods based on the practice of mindfulness (1). Within these methods, ,participants explicitly learn how to develop a mindful approach to their problems and how to use mindfulness in their everyday lives“ (7). Their attention focuses ,on the present moment, looking around and noticing what we normally cannot see. It teaches us to focus on colors, noises, smells, even the ones we have not perceived before. The main point is not to judge, evaluate or expect anything" (7).

When practicing mindful behavior, the parents were asked to fully concentrate on the present moment or the concrete activity they were doing, or about to do, at the moment. This activity must not be related to their child. The task of the parents was to be aware of the present moment and the performed activity without being distracted by unrelated thoughts, images or emotions. The goal was to concentrate the psychological flexibility of the parents and their openness toward various aspects of this activity by focusing their full attention on the activity itself, rather than its results. In the course of mindful behavior, the attention of the parents is shifted, without being forced, to the individual aspects of a particular activity that are then explored from various perspectives. One of the common examples is manual dish-washing when one practices mindful behavior through being aware of the warm sensation in one's hands, the shine of clean dishes or body movements. After this regular-session training was finished, each parental couple had their separate evaluation session. The training of mindful behavior that lasted several months and was modified to meet the needs of the parents of extremely premature infants has proven to be effective in attenuating the ruminations about the condition of their child or the anxiety related to the impact of COVID-19.

Each family that participated in the research experienced the birth of an extremely premature infant differently. Also, they come to terms with the new situation differently, based on the living, social, and economic conditions in the country they live in. The stance of the families on their situation can be divided into several categories: - the families that accept the situation as it is, being aware that they have to come to terms with it in a certain way. These families have opted for a strategy of acceptance. They strive to accommodate to the situation as much as possible, operating within their resources;

- the families that perceive the situation optimistically. The survey results have shown that the families with this attitude predominantly seek to minimize the image of the difficult situation. In the case of these families one can observe a defense mechanism that lapses into an escape strategy. In this regard, too, the training of mindful behavior was very efficient for the families. It helped the families to see how they can ,disregard“" the challenging situation without trying to escape;

- the families that have a categorically negative attitude to the emerged situation. These families are convinced that the scenario will be the worst possible, including the severe disabilities of the child. Being under permanent pressure, everyday situations are very stressful for them. Members of these families are often liable to panic and angst. They regularly tend the child with exaggerated and irrelevant protection that results in ever greater tension and stress. The practice of mindful behavior enables them to better realize the ,here and now.“ It instructs them to eliminate the ruminations about various concerns. This practice can be particularly 
efficient if the families pursue it through various meditation techniques, focused on, for instance, breathing, body, motion, the uncritical observation of thoughts and images, that significantly contribute to reducing tension, anxiety, and stress.

\section{Discussion}

The in-depth online interview with the families was challenging for many parents as it recalled the painful times when they had undergone the excessive stress due to the threat to the life of their child. Many parents were moved by intense emotions during the conversation. With regard to the fact that the survey was conducted during the spread of the COVID-19 pandemic, this issue echoed with the parents immensely, exacerbating their stress and angst. As a response to this situation, numerous parents indicated depression or post-traumatic stress disorder (PTSD). This was one of the reasons why the research also included several months of modified mindful behavior training intended for the needs of the parents of extremely premature infants. It helped them develop a decentered distance from their own negative thoughts and emotions by concentrating on a specific activity.

Furthermore, the research highlighted the importance that those around the parents of extremely premature infants often do not understand what the parents must go through, nor can they fathom what the care of such an infant involves and what his or her parents need to face.

The theme of extremely premature infant care and of the efficient support for their parents is becoming ever more relevant in this period, affected by different COVID-19-related measures. At the same time, however, one needs to keep in mind that such care and support must also take into consideration the idea of upholding the dignity of the parents of these children who have suddenly and unexpectedly happened to be in a difficult situation and are in need of social support in all possible areas; what efficient strategies and methods can help these parents mobilize their internal resources; how to let them know that both their child and themselves matter and are a visible and important part of society or the community - that they are valuable and that somebody genuinely and sincerely cares for them...

\section{Conclusion}

Today, a system of social relationships with people participating in a communicational network is becoming ever more relevant. These relationships are perceived as subjectively important for maintaining one's own identity and mental balance (3). One finds security in positive social relationships that help one overcome challenging life situations and represent a common source to enable experiencing the meaningfulness of life. The phenomenon of social support thus represents a social pool from which one can benefit in case of need; it influences the way one copes with difficult, challenging, and stressful events and alleviates their consequences. It is also related to the quality of life and an experienced happy life in the case of the families of extremely premature infants.

The results of this survey can be applied to produce analyses that will serve as the basis for future relevant and innovative research on the impact of COVID-19 for the global population.

\section{References}

1. KABAT-ZINN J (1990) Full catastrophe living: Using the wisdom of your body and mind to face stress, pain, and illness. New York: Delta Trade Paperback/Bantam Dell.

2. KRIVOHLAVY J (2009) Nurse and stress. Praha: Grada Publishing.

3. Levicka, J (2004) Basic of social work. Trnava: FZaSP TU.

4. SMIDOVA M, TREBSKI K, NEMCIKOVA M (2019) Quality in long-term care: Central European people-centered assessment principles and their calls for an efficient interdisciplinary dialogue. In Acta Missiologica, 201913 (2) p. 209. ISSN: 1337-7515 (Print) ISSN: 2453-7160 (On-line) https://www.actamissiologica.com/.

5. PERI H A, SUBRAMANIAN S, SLADECKOVA V, BYDZOVSKY J, DURCOVA B, KUBALIKOVAZ, OLAH M, MATULNIKOVA L, DOKTOROV A, BERESOVA A, KUBIK F, FULA M, OTRUBOVA J, KALATOVA D, KUKUCKOVA E, JURINOVA S, BENCA J, SHAHUM A, HOY LEANG HOINAND CHENG HOIN, SETA S/ Early detection of adverse therapy reaction in orphan children with AIDS (short communication) 
In: Acta Missiologica. - ISSN 1337-7515. Vol. 13, no. 2 (2019) p. 184-187.

6. TRIZULIAKOVA J, KRCMERYOVA L, MOJZESOVA M (2020) Prenatal Palliative Care and Perinatal Hospice - New Challenges in Caring for the Precious Gift of Life in its Fragility. In Clinical Social Work and Health Intervention, 202011 (1) p. 49. ISSN: 20769741/online ISSN: 2222-386x/Print DOI 10.22359/cswhi_11_1.

7. ZAMKOWSKA A, OLZEWSKI M (2020): Families with a Disabled Child's Perception of Societal Attitudes Towards Them. In Clinical Social Work and Health Intervention, 202011 (1) p. 57. ISSN: 2076-9741/online ISSN: 2222-386x/Print DOI 10.22359/cswhi_11_1.

8. VARGHESE J et al (2020): Certain negative consequences related to the coronavirus pandemic and relevant possible solutions. In Acta Missiologica, 201913 (2) p. 85. ISSN: 13377515 (Print) ISSN: 2453-7160 (On-line) https://www.actamissiologica.com. 